\title{
Chronic Tyrosinemia Associated with 4-Hydroxyphenylpyruvate Dioxygenase Deficiency with Acute Intermittent Ataxia and without Visceral and Bone Involvement
}

\author{
O. GIARDINI, A. CANTANI, N.G. KENNAWAY ${ }^{(28)}$ AND P. D'EUFEMIA

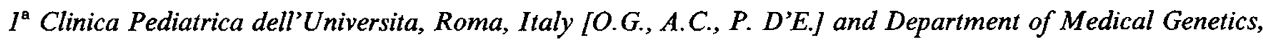 \\ Oregon Health Sciences University, Portland, Oregon USA [N.G.K.]
}

\section{Summary}

A 17-month-old girl, with acute intermittent ataxia and drowsiness, had hypertyrosinemia (serum tyrosine, $62 \mu \mathrm{mole} / \mathrm{dl}$ ) and phenolic aciduria in the absence of hepatic, renal, eye or skin lesions. Serum methionine and urinary $\delta$-aminolevulinic acid concentrations were normal. Her psychomotor development was also normal. Protein restriction and vitamin $\mathrm{C}$ therapy failed to correct the biochemical abnormality. Liver biopsy was histologically normal.

Analysis of the enzymes in the liver biopsy, taken at 25 months of age, showed no detectable activity of 4-hydroxyphenylpyruvate dioxygenase (4HPPD), either in whole homogenate or cytosol fraction. Mixing experiments revealed no inhibitor of either 4HPPD or tyrosine aminotransferase (TAT).

TAT in unfractionated liver was $0.23 \mu \mathrm{mole} / \mathrm{mg}$ protein/h (control, 0.10-0.30 $\mu$ mole/mg protein $/ \mathrm{h} ; \boldsymbol{n}=5$ ). In mitochondria, TAT was $0.24 \mu \mathrm{mole} / \mathrm{mg}$ protein/h (control, 0.09-0.12 $\mu \mathrm{mole} / \mathrm{mg}$ protein $/ \mathrm{h} ; n=3$ ) whereas in cytosol fraction it was $0.23 \mu \mathrm{mole} / \mathrm{mg}$ protein/h (control, $0.27-0.44 \mu \mathrm{mole} / \mathrm{mg}$ protein $/ \mathrm{h} ; n=3$ ). Glutamate dehydrogenase activity appeared in the cytosol fraction suggesting some rupture of mitochondria during fractionation of the patient's liver and indicating that true cytosol TAT might be somewhat lower than indicated; however, the kinetics of the patient's cytosol TAT were normal: $\mathrm{Km}$ for tyrosine, $4.5 \times 10^{-3} \mathrm{M}$ (control, $4.0 \times 10^{-3} \mathrm{M}$ ); $\mathrm{Km}$ for $\alpha$-ketoglutarate, $98 \times 10^{-6} \mathrm{M}$ (control, $75 \times 10^{-6} \mathrm{M}$ ); approximate $\mathrm{Km}$ for pyridoxal phosphate, $2.1 \times 10^{-6} \mathrm{M}$ (control, $\left.4.0 \times 10^{-6} \mathrm{M}\right)$. Vmax in patient liver was $0.37 \mu \mathrm{mole} / \mathrm{mg}$ protein/h (control, $0.88 \mu \mathrm{mole} / \mathrm{mg}$ protein $/ \mathrm{h}$ ). These data argue against a primary abnormality of TAT but are consistent with a defect of 4 HPPD; thus, this patient appears to represent a previously undescribed form of tyrosinemia.

\section{Speculation}

Demonstration of deficient activity of 4-hydroxyphenylpyruvate dioxygenase in a patient with a unique form of tyrosinemia raises the possibility that a similar defect may be present in several other patients with atypical forms of tyrosinemia.

There are two well recognized forms of hereditary tyrosinemia. In the first (type I), associated with failure to thrive, rickets, Fanconi syndrome, and progressive liver failure, the levels of blood tyrosine and frequently methionine are elevated and there is increased urinary excretion of tyrosine and its metabolites (tyrosyluria) as well as increased $\delta$-aminolevulinic acid. Deficient activity of a number of enzymes in the liver, including cytosol tyrosine aminotransferase (TAT; EC 2.6.1.5.) and 4-hydroxyphenylpyruvate dioxygenase (4HPPD; EC 1.13.11.27) has been reported. Recently, a deficiency of hepatic fumarylacetoacetate hy- drolase (EC 3.7.1.2) has been demonstrated in several patients (18) and is now felt to be the primary enzyme defect in this disease.

Tyrosinemia type II has been described in over twenty patients, most of whom have manifest the Richner-Hanhart syndrome with severe persistent keratitis and more variable hyperkeratosis on the fingers and palms of the hands and soles of the feet. These lesions respond completely to dietary tyrosine restriction. Blood tyrosine is greatly elevated and there is massive tyrosyluria. Absent activity of hepatic cytosol TAT has been demonstrated in two patients $(9$, 16) and a milder deficiency has been reported in two other patients, in liver (11) and fibroblasts (4) respectively.

Another form of tyrosinemia has been reported in two children with severe metabolic acidosis who excreted the unusual tyrosine metabolites hawkinsin and cis- and trans-4-hydroxycyclohexylacetic acids in the urine $(3,22,26)$. The primary abnormality is thought to be in the rearrangement of an intermediate formed in the 4HPPD reaction.

We now report a case of persistent tyrosinemia and tyrosyluria associated with deficient activity of 4HPPD in liver. The clinical picture was characterized by sporadic ataxia and drowsiness in a child who was otherwise normal.

\section{MATERIALS AND METHODS}

Case report. K.W. was the second child of healthy, unrelated, Egyptian parents. Pregnancy and delivery were uncomplicated. Birthweight was $3200 \mathrm{~g}$ and the neonatal period was normal. No problems occurred until 17 months of age, when the child was admitted to the Pediatric Clinic of Rome University because of acute ataxia followed by drowsiness. On examination she demonstrated confusion, motor incoordination, muscular hypotonia and absent tendon reflexes. The pupils were unreactive to light, there was no response to painful stimuli, breathing was noisy and the liver edge was $2 \mathrm{~cm}$ below the costal margin. The examination was otherwise normal. Blood glucose was normal. Routine toxicologic analysis of serum and urine by gas-liquid chromatography revealed no poisonous agents.

The child was treated intravenously with fluids, glucose, and electrolytes. After $8 \mathrm{~h}$, response to stimuli and reflexes reappeared and in the following days, voluntary movements improved although her gait was ataxic until day 10 .

During this time, routine laboratory tests, including SGOT (20$38 \mathrm{IU} /$ liter), SGPT (11-20 IU/liter), total serum protein $(8 \mathrm{~g} /$ liter), alkaline phosphatase (110 IU/liter), total serum cholesterol $(125 \mathrm{mg} / \mathrm{dl})$, and triglycerides $(48 \mathrm{mg} / \mathrm{dl})$ were normal. Glomerular filtration rate (GFR), creatinine, creatinine clearance, and phosphate reabsorption were also normal. Plasma amino acids (Table 1) established the diagnosis of tyrosinemia. Fundus examination, E.E.G., E.C.G., skull x-rays and psychomotor devel- 
Table 1. Serum aminoacid levels ( $\mu$ mole/dl)

\begin{tabular}{|c|c|c|c|c|c|c|}
\hline \multirow{3}{*}{$\begin{array}{l}\text { Age } \\
\text { Dietary protein }(\mathrm{g} / \mathrm{kg} / \text { day })\end{array}$} & \multicolumn{4}{|c|}{ Patient } & \multirow{3}{*}{$\begin{array}{l}\text { Mother } \\
\text { normal }\end{array}$} & \multirow{3}{*}{ 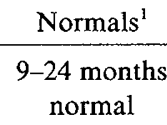 } \\
\hline & 17 months & 19 months & 27 months & 42 months & & \\
\hline & normal & 1.0 & 1.0 & normal & & \\
\hline Phenylalanine & 7.6 & 7.9 & 6.2 & 10.2 & 5.3 & $2.3-6.9$ \\
\hline Methionine & 2.6 & 5.4 & 3.3 & 2.8 & 3.4 & $0.3-2.9$ \\
\hline
\end{tabular}

'From Soupart (24).

opment were also normal (I.Q. 123). Skeletal x-rays showed mild osteoporosis but no rickets.

After the patient had recovered, an oral loading test with $\mathrm{L}$ tyrosine $(100 \mathrm{mg} / \mathrm{kg}$ in fruit juice acidified with ascorbic acid) was performed. The serum tyrosine increased from $80 \mu \mathrm{mole} / \mathrm{dl}$ at zero time to $101 \mu \mathrm{mole} / \mathrm{dl}$ at $1 \mathrm{~h}, 104 \mu \mathrm{mole} / \mathrm{dl}$ at $2 \mathrm{~h}$, and 107 $\mu$ mole $/ \mathrm{dl}$ at $3 \mathrm{~h}$. and the child became drowsy with mild ataxia which lasted $4 \mathrm{~h}$. An open liver biopsy, performed at 25 months (after written informed consent was obtained) was histologically normal.

Further clinical course. On day 24 the infant was dismissed in good condition, on a low-protein diet $(1 \mathrm{~g} / \mathrm{kg} /$ day $)$. There was no recurrence of symptoms except for a painful erythema of the limbs that disappeared after a few days. Serum tyrosine remained high despite protein restriction.

The girl has been on a regular diet since the age of 30 months and has continued excellent growth and psychomotor development. When last seen, at $3 \frac{1}{2}$ years of age, her protein intake was normal and she was doing well. Her height was $96.5 \mathrm{~cm}(25$ th percentile) and her weight was $15.4 \mathrm{~kg}$ (50th percentile); physical examination was normal. The serum tyrosine level was 69.6 $\mu$ mole/dl (Table 1).

Gas chromatography of tyrosine metabolites. Urine was acidified to $\mathrm{pH} 1$, extracted 3 times with 2 volumes of ethyl acetate, dried over sodium sulfate, filtered, evaporated in vacuo and derivatized with a 1:1 mixture of Sil Prep (Applied Science) and BSTFA (Pierce) at room temperature, overnight. Phenolic acids were quantitated on a Hewlett-Packard model 5830 A gas chromatograph equipped with a hydrogen flame ionization detector and an $8 \mathrm{ft} \times 2 \mathrm{~mm}$ column of $3 \%$ OV101 on 80/100 mesh Supelcoport (Supelco Inc.), using 4-phenylbutyric acid as internal standard. Identity of compounds was confirmed by gas chromatography/ mass spectrometry on a Finnegan model 4021 mass spectrometer equipped with an all glass jet separator. Selective ion monitoring at $302,287,212,204,195,147,123,95$, and $81 \mathrm{~m} / \mathrm{e}$ was used in an attempt to detect cis- or trans-4-hydroxycyclohexylacetic acids (22).

Hepatic enzyme studies. Control liver was obtained within $4 \mathrm{~h}$ of death from children who died of trauma (\#177 age $15 \mathrm{yr}$ ), lactic acidosis (\#186, age 4 yr), nonketotic hyperglycinemia (\#240 age 17 months), and Menkes disease ( $\# 262$ age 28 months). Control 247 was a biopsy from a patient of 14 months with hypermethioninemia but no tyrosinemia or evidence of hepatic disease and control 178 was a biopsy of normal hepatic tissue from a 3-yearold patient with a hepatic hamartoma. Fresh tissue was homogenised in 19 volumes of $0.25 \mathrm{M}$ sucrose containing $10 \mathrm{mM}$ Tris or

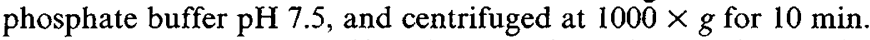
The supernatant was centrifuged at $20,000 \times g$ for $30 \mathrm{~min}$ and the resulting supernatant carefully separated from the mitochondrial pellet. All procedures were carried out at $0-4^{\circ} \mathrm{C}$. Fractionation of the patient's biopsy material was performed immediately as described above. The fractions were maintained at $-70^{\circ} \mathrm{C}$ for $3 \mathrm{wk}$, shipped on dry ice from Italy to the USA where they arrived still frozen, and maintained at $-70^{\circ} \mathrm{C}$ until assay. The mitochondrial pellet was suspended in a small volume of $10 \mathrm{mM}$ Tris, $\mathrm{pH} 7.5$ and sonicated three times for $15 \mathrm{sec}$ each at 30-40 watts on a Braunsonic model 1510 sonicator with a micro probe. For measurement of enzyme activity in unfractionated homogenate, tissue was homogenized in $10 \mathrm{mM}$ Tris $\mathrm{pH} 7.5$ as above, centrifuged at
$1000 \times g$ for $10 \mathrm{~min}$ and the supernatant sonicated as described. All fractions were stored at $-70^{\circ} \mathrm{C}$.

TAT was measured by the radiochemical procedure of Fellman et al. $(8,9)$ except that the final concentration of $\alpha$-ketoglutarate was $10 \mathrm{mM}$, the buffer was $0.2 \mathrm{M}$ Tris, $\mathrm{pH} 7.5$ and $\mathrm{N}, \mathrm{N}^{\prime}$ diethyldithiocarbamate was omitted. This reaction is based on the release of $\left[{ }^{3} \mathrm{H}_{2} \mathrm{O}\right]$ from L-tyrosine (side-chain-2, 3, $-{ }^{3} \mathrm{H}$; Amersham) the $\left[{ }^{3} \mathrm{H}_{2} \mathrm{O}\right]$ being distilled in Thunberg tubes and measured by liquid scintillation counting. 4HPPD was measured by method II of Lindblad et al. (17). The incubation mixture contained bovine liver catalase (Sigma, $0.8 \mathrm{~g}$ /liter), glutathione (10 mM), 2, 6-dichloroindophenol (0.15 mM), Tris buffer, pH $7.5(0.2 \mathrm{M})$ and 4-hydroxyphenyl- $\left[1-{ }^{14} \mathrm{C}\right]$ pyruvate $[0.2 \mathrm{mM} ; 5.2 \mu \mathrm{Ci} / \mathrm{mmole}$, generously provided by Dr. J. H. Fellman (7)] in a final volume of 2.0 $\mathrm{ml}$. The sample was pre-incubated for $20 \mathrm{~min}$ at $4^{\circ} \mathrm{C}$ with all the above components except 4-hydroxyphenylpyruvate. This was then added and the mixtures incubated at $37^{\circ} \mathrm{C}$ for $15 \mathrm{~min}$ in stoppered vials fitted with a filter paper disc containing $0.04 \mathrm{ml}$ of hyamine hydroxide (New England Nuclear) suspended from the stopper. The reaction was stopped with $0.2 \mathrm{ml}$ of $1 \mathrm{~N}$ sulfuric acid and incubation continued for a further $30 \mathrm{~min}$ to allow absorption of the evolved $\left[{ }^{14} \mathrm{CO}_{2}\right]$ on the filter paper. Radioactivity was determined by liquid scintillation counting in $10 \mathrm{ml}$ of $0.4 \%$ omnifluor (New England Nuclear) in toluene:ethanol 4:1. Lactate dehydrogenase (E.C. 1.1.1.27) and 6-phosphogluconate dehydrogenase (E.C. 1.1.1.44) were determined as described previously (15) and glutamate dehydrogenase (E.C. 1.4.1.3) by the method of Beaufay et al. (1). Protein was determined by the method of Lowry et al. (20).

$\mathrm{Km}$ values of tyrosine and $\alpha$-ketoglutarate for TAT were determined on undialysed cytosol fractions and calculated from Lineweaver-Burke double reciprocal plots. The $\mathrm{Km}$ for pyridoxal phosphate was obtained on samples which had been dialysed

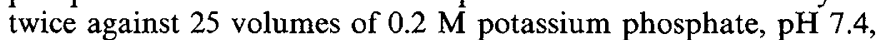
containing $5 \mathrm{mM}$ mercaptoethanol and $1 \mathrm{mM}$ EDTA, for $2 \mathrm{~h}$ each (4). Because dialysis did not result in complete removal of pyridoxal phosphate, as evidenced by the appreciable enzyme activity in samples to which no pyridoxal phosphate was added, a correction was made for the residual amount of pyridoxal phosphate in the sample after dialysis by extrapolating the curve of velocity versus substrate to zero velocity. The approximate $\mathrm{Km}$ for pyridoxal phosphate was then obtained from the double reciprocal plots.

\section{RESULTS}

The patient's urine gave a positive reaction to 2,4-dinitrophenylhydrazine, suggesting the presence of an $\alpha$-ketoacid, and to nitrosonaphthol, indicating the presence of tyrosine metabolites. Serum and urine levels of tyrosine were much increased: 62 $\mu$ mole $/ \mathrm{dl}$ and $9.39 \mu \mathrm{mole} / \mathrm{kg} / 24 \mathrm{~h}$, respectively. Other aminoacids showed no consistent abnormalities. Serum methionine was normal except on one occasion when several other amino acids were also mildly elevated (Table 1 ). Urinary $\delta$-aminolevulinic acid was normal. The urine contained high levels of $p$-hydroxyphenyllactic acid (pHPLA, $3.80 \mathrm{mg} / \mathrm{mg}$ creatinine), $p$-hydroxyphenylpyruvic acid (pHPPA, $0.80 \mathrm{mg} / \mathrm{mg}$ creatinine) and $p$-hydroxyphenylacetic acid(pHPAA, $0.27 \mathrm{mg} / \mathrm{mg}$ creatinine). Only pHPAA $(0.005-0.042$ $\mathrm{mg} / \mathrm{mg}$ creatinine) is normally detected in control urines (2). The 
identity of these metabolites was confirmed by mass spectrometry; selective ion monitoring gave no evidence for the presence of cisor trans-4-hydroxycyclohexylacetic acids.

The stability of the hepatic enzymes from control tissue to storage at $-70^{\circ} \mathrm{C}$ was investigated (Fig. 1). All showed slow decline but retained at least $50 \%$ of their original activity even after a 12-month period.

The results of the enzyme analysis of the patient's liver biopsy are shown in Table 2. 4HPPD activity was undetectable in both whole homogenate and cytosol. Mixing experiments indicated that

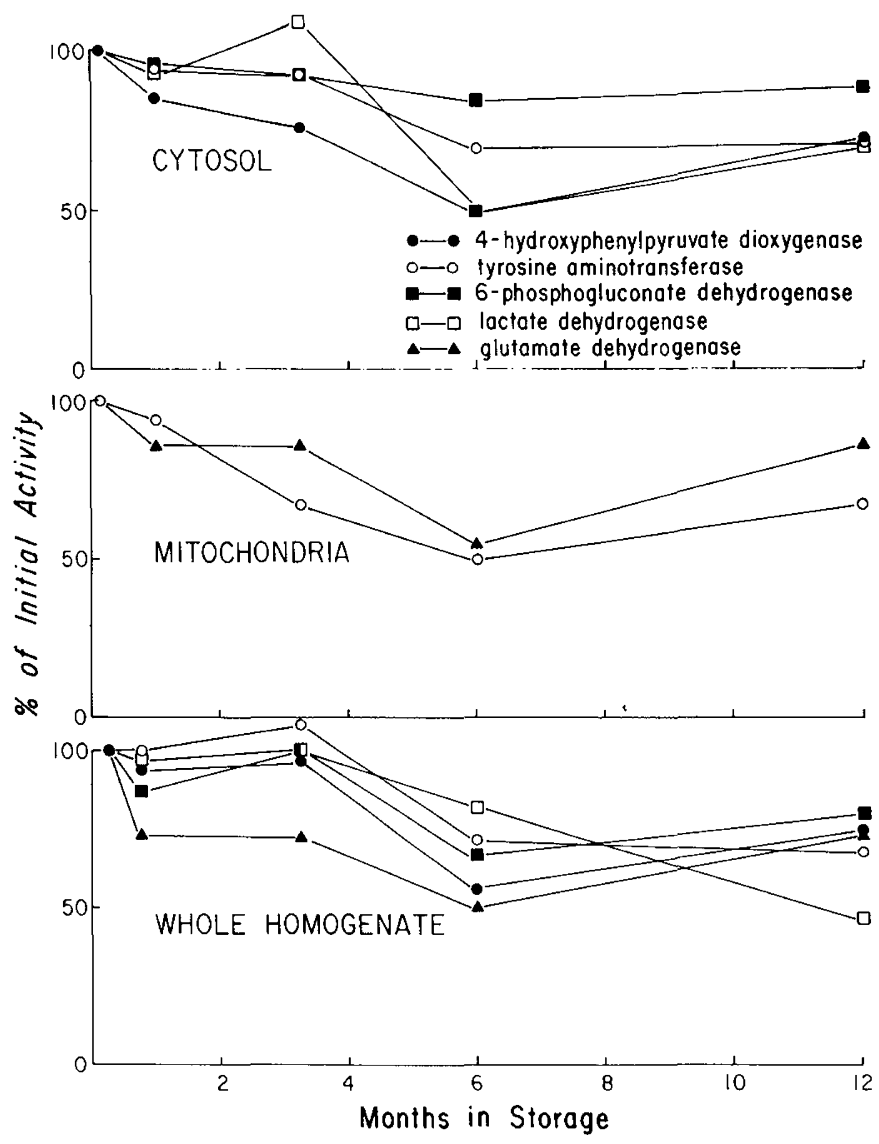

Fig. 1. Stability of hepatic enzymes to storage at $-70^{\circ} \mathrm{C}$. no inhibitor, either of TAT or of 4HPPD, was present in the cytosol. TÁT activity was normal in whole tissue, slightly lower than normal in cytosol and approximately twice normal in mitochondria. Mitochondrial TAT in tissues from three controls represented $11-17 \%$ of the total TAT activity whereas in the patient it was $19 \%$ of the total; however, the activity of glutamate dehydrogenase, a mitochondrial enzyme, was much higher in the patient's cytosol than in the controls, suggesting considerable rupture of mitochondria during the fractionation procedure. In order to investigate whether the kinetics of TAT were normal, $\mathrm{Km}$ values for both substrates and coenzyme were determined (Table 3).

\section{DISCUSSION}

Cytosolic TAT, the first and rate limiting enzyme of tyrosine metabolism, catalyses the transamination of tyrosine and $\alpha$-ketoglutarate to pHPPA and glutamate and requires pyridoxal phosphate as coenzyme. In the mitochondria, tyrosine can be transaminated by aspartate aminotransferase (EC 2.6.1.1), which utilizes a wide range of substrates (21). It is not thought to be involved in normal tyrosine catabolism. The second enzyme in the pathway, 4HPPD, converts pHPPA to homogentisic acid. Absent activity of hepatic cytosol TAT (tyrosinemia type II) is associated with the Richner-Hanhart syndrome, tyrosinemia, and tyrosyluria. The eye and skin lesions respond rapidly to dietary tyrosine restriction. The enzyme defect was first described by Fellman et al. (9) in the patient subsequently reported by Kennaway and Buist (13); mitochondrial TAT and 4HPPD were normal. In this condition pHPPA, the product of the missing enzyme is thought to be formed by mitchondrial transamination of tyrosine in many tissues which lack the 4HPPD. The pHPPA thus formed would enter the blood stream and utimately be cleared by the kidney $(6,14)$.

Table 3. Kinetic characteristics of cytosol tyrosine aminotransferase

\begin{tabular}{lcc}
\hline & Control & Patient \\
\hline V max & 0.88 & 0.37 \\
Km for tyrosine & $4.0 \times 10^{-3} \mathrm{M}$ & $4.5 \times 10^{-3} \mathrm{M}$ \\
$\mathrm{Km}$ for $\alpha$-ketoglutarate & $75 \times 10^{-6} \mathrm{M}$ & $98 \times 10^{-6} \mathrm{M}$ \\
$\mathrm{Km}$ for pyridoxal phosphate ${ }^{2}$ & $4.0 \times 10^{-6} \mathrm{M}$ & $2.1 \times 10^{-6} \mathrm{M}$ \\
\hline \multicolumn{3}{c}{ ( $\mu$ mole/mg protein/h). } \\
${ }^{2}$ These values are approximations (see "Materials and Methods" sec- \\
tion).
\end{tabular}

Table 2. Enzyme activities in liver fractions ${ }^{1}$

\begin{tabular}{|c|c|c|c|c|c|c|c|}
\hline & Time in storage & $\begin{array}{l}\text { Tyrosine amino- } \\
\text { transferase }\end{array}$ & $\begin{array}{c}\text { 4-Hydroxyphenylpyruvate } \\
\text { dioxygenase }\end{array}$ & $\mathbf{L D H}^{2}$ & $6 \mathrm{PGD}^{2}$ & $\mathrm{GDH}^{2}$ & $\begin{array}{c}\text { Protein } \\
\text { (mg/g wet wt) }\end{array}$ \\
\hline \multicolumn{8}{|c|}{ Whole homogenate } \\
\hline Control 177 & 18 months & 0.13 & 0.43 & 24 & 1.1 & 2.2 & 172 \\
\hline Control 178 & 13 months & 0.14 & 0.67 & 44 & 1.3 & 2.5 & 129 \\
\hline Control 186 & 11 months & 0.10 & 0.61 & 44 & 2.3 & 1.7 & 126 \\
\hline Control 240 & $13 \mathrm{wk}$ & 0.27 & 0.31 & 39 & 1.5 & 1.6 & 137 \\
\hline Control 262 & 12 days & 0.30 & 0.36 & 28 & 1.6 & 1.6 & 152 \\
\hline Patient K.W. & 14 wk & 0.23 & undetectable & 31 & 1.6 & 1.7 & 102 \\
\hline \multicolumn{8}{|l|}{ Cytosol } \\
\hline Control 247 & 7 days & 0.36 & 0.38 & 37 & 2.0 & 0.25 & 155 \\
\hline Control 240 & $13 \mathrm{wk}$ & 0.44 & 0.55 & 74 & 2.3 & 0.49 & . 88 \\
\hline Control 262 & 12 days & 0.27 & 0.64 & 55 & 1.7 & 0.34 & 97 \\
\hline Patient K.W. & 12 wk & 0.23 & undetectable & 38 & 2.2 & 2.5 & 68 \\
\hline \multicolumn{8}{|l|}{ Mitochondria } \\
\hline Control 247 & 7 days & 0.09 & & & & 1.5 & 78 \\
\hline Control 240 & $13 \mathrm{wk}$ & 0.12 & & & & 1.9 & 37 \\
\hline Control 262 & 12 days & 0.12 & & & & 2.7 & 42 \\
\hline Patient K.W. & 12 wk & 0.24 & & & & 3.1 & 15 \\
\hline
\end{tabular}

${ }^{1}$ Units of measurement for tyrosine aminotransferase, 4-hydroxyphenylpyruvate dioxygenase, LDH, 6PGD, and GDH: $\mu \mathrm{moles} / \mathrm{mg}$ protein/h.

${ }^{2} \mathrm{LDH}$, lactate dehydrogenase; 6PGD, 6-phosphogluconate dehydrogenase; and GDH, glutamate dehydrogenase. 
Although many cases of tyrosinemia type II have been recognized, absent cytosol TAT activity has only been reported in one other patient (16); however, Goldsmith et al. (11) described a mildly retarded 55-year-old male with the Richner-Hanhart syndrome and tyrosinemia. Hepatic cytoplasmic TAT was half the mean control value and although within the control range, this was assumed to be responsible for the tyrosinemia. It seems to us unlikely that tyrosinemia would result from a reduction of only $50 \%$ of normal enzyme activity. These findings could however be explained by a mutant TAT with decreased affinity for substrate or cofactor, because the enzyme assays were presumably performed under saturating concentrations. Alternatively, this patient might represent a case of 4HPPD deficiency. Unfortunately, this enzyme activity was not measured.

Tyrosinemia and tyrosyluria were reported in another patient, aged 3 years, with developmental delay and seizures but no other manifestations of the Richner-Hanhart syndrome (4). Enzyme assays in cultured skin fibroblasts revealed normal cytosol TAT under saturating conditions, normal Vmax and $\mathrm{Km}$ for tyrosine, but markedly decreased $\mathrm{Km}$ for pyridoxal phosphate. 4HPPD was normal. This report is interesting, not only because of the unique nature of the enzyme defect but because enzymes were detectable for the first time in cultured skin fibroblasts. This conflicts with our failure to detect these enzymes in fibroblasts but this could be due to differences in the culture conditions or some other unknown factor. These reports illustrate the importance of studying enzyme kinetics in patients with apparently normal levels of enzyme activity.

Several other patients with tyrosinemia and tyrosyluria have been described who do not clearly fit the picture of tyrosinemia type I or II. The patient described by Louis et al. (19) was a 35year-old male with only moderate mental retardation and marked tremor of the hands, head, and feet. Enzymatic studies of this patient were inconclusive but suggested a possible deficiency of 4HPPD activity (5). Wadman et al. (25) described a patient with severe mental retardation and cataracts; enzyme studies were not performed. Finally, Danks et al. $(3,22)$ reported a patient with mild prolonged, transient tyrosinemia who presented with severe metabolic acidosis in whom the unusual tyrosine metabolites, hawkinsin and cis- and trans-4-hydroxycyclohexylacetic acid were found in the urine. It was postulated that these metabolites were derived from an intermediate of the 4HPPD reaction and that the child and her mother were heterozygous for a defect of this enzyme which was able to oxidize and decarboxylate pHPPA but was unable to rearrange the intermediate to homogentisic acid. A second family, with five affected members in three successive generations, has recently been described (26).

The patient described here differs from all other reported patients with prolonged tyrosinemia because of the absence of any persistent clinical symptom. In particular, her development is normal, she does not have liver or kidney dysfunction, nor does she have the eye or skin lesions characteristic of tyrosine toxicity in the Richner-Hanhart syndrome. The cause of her transient ataxia and drowsiness is unknown although, on at least one occasion, it was associated with an increase in the concentration of serum tyrosine. The child's normal psychomotor development (she learned very quickly to speak Italian) indicated that the hypertyrosinemia per se cannot account for mental impairment. This has previously been suggested by Pelet et al. (23) with reference to four other patients $(5,10,12)$.

Our patient has persistent hypertyrosinemia and tyrosyluria. The serum tyrosine was not modified by high doses of vitamin $C$ nor, surprisingly, by a low protein diet. Strict adherence to this diet could not be verified and might explain this finding; in view of the mild clinical course, more severe tyrosine restriction was not felt warranted. The absence of activity of 4HPPD in liver is unlikely to be due to instability of this enzyme to freezing for 12 wk because enzymes in the control tissue showed little decline in activity over this period, whether stored as intact tissue or supernatant fraction. In all controls studied, 4HPPD activity was readily detectable even in tissues stored up to 18 months. The patient's liver showed no evidence of an inhibitor of this enzyme, suggesting that 4HPPD deficiency represents the primary enzyme defect in this form of tyrosinemia. 4HPPD catalyses a complex reaction which involves hydroxylation of the aromatic ring, decarboxylation, and rearrangement of the side chain. Because our assay method is based on the release of $\mathrm{CO}_{2}$ from pHPPA, the defect in our patient must be at an earlier step of this enzyme activity than in Danks' patient who excreted hawkinsin and the hydroxycyclohexylacetic acids, metabolites presumed to be formed after hydroxylation and decarboxylation of pHPPA. This is consistent with our failure to demonstrate these metabolites in the urine from our patient. Absence of metabolic acidosis in our patient and most other patients with tyrosinemia suggests that the more commonly observed tyrosine metabolites, pHPPA, pHPLA and pHPAA, are cleared more rapidly by the kidneys than the acids which accumulate in Danks' patient.

The specific activity of TAT in mitochondria from the patient was twice normal, a finding previously observed in two patients with cytosol TAT deficiency $(10,15)$. Although TAT activity in cytosol was close to the lower limit of normal, the apparent rupture of a major proportion of mitochondria suggests that a considerable amount of the cytosol TAT activity could have derived from this source; thus, it is not possible to rule out at least a partial deficiency of cytosol TAT in this patient. It does however seem unlikely that this represents the primary enzyme defect, first because it is certainly not totally deficient and second because the kinetics of the enzyme in the patient were entirely normal.

In conclusion, we have described a patient with transient ataxia and drowsiness and no persistent clinical abnormality, who has tyrosinemia and tyrosyluria associated with deficient activity of hepatic 4HPPD. It is possible that several other patients, particularly those described by Wadman et al. (25), Faull et al. (5), and Goldsmith et al. (11) may have had a similar enzyme defect.

\section{REFERENCES AND NOTES}

1. Beaufay, H., Bendall, D. S., Baudhuin, P., and deDuve, C.: Tissue fractionation studies. 12 Intracellular distribution of some dehydrogenases, alkaline deoxyribonuclease and iron in rat-liver tissue. Biochem. J., 73: 623 (1959).

2. Crawhall, J. C., Mamer, O., Tjoa, S., and Claveau, J. C.: Urinary phenolic acids in tyrosinemia. Identification and quantitation by gas chromatography-mass spectrometry. Clin. Chim. Acta, 34: 47 (1971).

3. Danks, D. M., Tippett, P., and Rogers, J.: A new form of prolonged transient tyrosinemia presenting with severe metabolic acidosis. Acta Paediatr. Scand. 64: 209 (1975).

4. DeGroot, G. W., Dakshinamurti, K., Allan, L., and Haworth, J. C.: Defect in soluble tyrosine aminotransferase in skin fibroblasts of a patient with tyrosinemia. Pediatr. Res., 14: 896 (1980).

5. Faull, K. F., Gan, I., Halpern, B., Hammond, J., Im, S., Cotton, R. G. H., and Danks, D. M.: Metabolic studies on two patients with nonhepatic tyrosinemia using deuterated tyrosine loads. Pediatr. Res., 11: 631 (1977).

6. Fellman, J. H., Buist, N. R. M., Kennaway, N. G., and Swanson, R. E.: The source of aromatic ketoacids in tyrosinaemia and phenylketonuria. Clin. Chim. Acta, 39: 243 (1972).

7. Fellman, J. H., Fujita, T. S., and Roth, E. S.: Assay, properties and tissue distribution of p-hydroxyphenylpyruvate hydroxylase. Biochim. Biophys. Acta, 284: 90 (1972).

8. Fellman, J. H. and Roth, E. S.: Inhibition of tyrosine aminotransferase activity by L-3, 4-dihydroxyphenylalanine. Biochemistry, 10: 408 (1971)

9. Fellman, J. H., Vanbellinghen, P. J., Jones, R. T., and Koler, R. D.: Soluble and mitochondrial forms of tyrosine aminotransferase. Relationship to human tyrosinemia. Biochemistry, 8: 615 (1969).

10. Garibaldi, L. R., Siliato, F., de Martini, I., Scarsi, M. R., and Romano, C.: Oculocutaneous tyrosinosis. Helv. Paediat. Acta, 32: 173 (1977).

11. Goldsmith, L. A., Thorpe, J., and Roe, C. R.: Hepatic enzymes of tyrosine metabolism in tyrosinemia II. J. Invest. Dermatol., 73: 530 (1979).

12. Halvorsen, S. and Skjelkvåle, L.: Tyrosine aminotransferase deficiency (TATD); first case diagnosed on newborn screening and successfully treated with PheTyr restricted diet from early age. Pediatr. Res., 11: 1017 (1977).

13. Kennaway, N. G. and Buist, N. R. M.: Metabolic studies in a patient with hepatic cytosol tyrosine aminotransferase deficiency. Pediatr. Res., 5: 287 (1971).

14. Kennaway, N. G., Buist, N. R. M., and Fellman, J. H.: The origin of urinary phydroxyphenylpyruvate in a patient with hepatic cytosol tyrosine aminotransferase deficiency. Clin. Chim. Acta, 41: 157 (1972).

15. Kennaway, N. G., Harwood, P. J., Ramberg, D. A., Koler, R. D., and Buist, N. R. M.: Citrullinemia: enzymatic evidence for genetic heterogeneity. Pediatr. Res., 9: 554 (1975).

16. Lemonnier, R., Charpentier, C., Odievre, M., Larregue, M., and Lemonnier, A. Tyrosine aminotransferase isoenzyme deficiency. J. Pediatr., 94: 931 (1979).

17. Lindblad, B., Lindstedt, G., Lindstedt, S., and Rundgren, M.: Purification and 
some properties of human 4-hydroxyphenylpyruvate dioxygenase (I). J. Biol Chem., 252: 5073 (1977).

18. Lindblad, B., Lindstedt, S., and Steen, G.: On the enzyme defects in hereditary tyrosinemia. Proc. Natl. Acad. Sci. (USA), 74: 4641 (1977).

19. Louis, W. J., Pitt, D. D., and Davies, H.: Biochemical studies on a patient with "tyrosinosis." Australia N. Zealand J. Med., 4: 281 (1974).

20. Lowry, O. H., Rosebrough, N. J., Farr, A. L., and Randall, R. J.: Protein measurement with the Folin phenol reagent. J. Biol. Chem., 193: 265 (1951).

21. Miller, G. E. and Litwack, G.: Purification, properties and identity of liver mitochondrial tyrosine aminotransferase. J. Biol. Chem., 246: 3234 (1971)

22. Niederwieser, A., Wadman, S. K., and Danks, D. M.: Excretion of cis- and trans4-hydroxycyclohexylacetic acid in addition to hawkinsin in a family with a postulated defect of 4-hydroxyphenylpyruvate dioxygenase. Clin. Chim. Acta, 90: 195 (1978).

23. Pelet, B., Antener, I., Faggioni, R., Spahr, A., and Gautier, E.: Tyrosinemia without liver or renal damage with plantar and palmar keratosis and keratitis (Hypertyrosinemia type II). Helv. Paediat. Acta, 34: 177 (1979).
24. Soupart, P.: Free amino acids of blood and urine in the human. In Holden, J. T. (Ed.) Amino acid pools. p. 220 (Elsevier, Amsterdam 1962).

25. Wadman, S. K., Van Sprang, F. J., Maas, J. W., and Ketting, D.: An exceptional case of tyrosinosis. J. Ment. Defic. Res., 12: 269 (1968)

26. Wilcken, B., Hammond, J. W., Howard, N., Bohane, T., Hocart, C., and Halpern, B.: Hawkinsinuria. A dominantly inherited defect of tyrosine metabolism with severe effects in infancy. N. Engl. J. Med., 305: 865 (1981).

27. We are grateful to Christine Jensen for performing the gas chromatographic and mass spectrometric analysis and to Drs. N. R. M. Buist and J. H. Fellman for their helpful discussion and advice.

28. Requests for reprints should be addressed to: Dr. Nancy G. Kennaway, Dept. of Medical Genetics, Oregon Health Sciences University, 3181 S.W. Sam Jackson Park Rd., Portland, OR 97201 USA.

29. This work was supported by a Biomedical Research Support Grant from the Oregon Health Sciences University.

30. Received for publication October 21,1981

31. Accepted for publication May 9, 1982. 